\title{
Short communication: Experimentally induced mastitis reduces weight shifting between the rear legs while standing in dairy cows
}

\author{
N. Chapinal, ${ }^{*} \dagger^{1}$ C. E. Fitzpatrick, ${ }^{* 2}$ K. E. Leslie, ${ }^{*}$ and S. A. Wagnerł \\ *Department of Population Medicine, University of Guelph, Guelph, Ontario, N1G 2W1, Canada \\ †Animal Welfare Program, University of British Columbia, Vancouver, V6T 1Z4, Canada \\ ‡Department of Animal Sciences, North Dakota State University, Fargo 58108
}

\section{ABSTRACT}

The objectives of this study were to evaluate changes in weight shifting between legs while standing on a weighing platform in response to endotoxin-induced clinical mastitis, and to evaluate the effect of the nonsteroidal antiinflammatory drug flunixin meglumine on weight distribution between legs while standing in dairy cattle with endotoxin-induced clinical mastitis. Clinical mastitis was induced in 10 primiparous and 9 multiparous lactating dairy cows (days in milk $=55$ \pm 12 ; mean \pm standard deviation) by intramammary infusion of $100 \mu \mathrm{g}$ of Escherichia coli lipopolysaccharide (LPS) into the right rear quarter. Four hours later, 10 animals were randomly assigned to receive flunixin meglumine intravenously $(2.2 \mathrm{mg} / \mathrm{kg}$ of body weight; treated group) and 9 received an equivalent volume of sterile isotonic saline solution (control group). Body temperature was monitored rectally $3 \mathrm{~d}$ before LPS infusion, immediately before LPS infusion, and 4, 7, 10, 13, 16, and $28 \mathrm{~h}$ after LPS infusion. The weight applied to each leg was recorded while cows were standing on a weighing platform on the day before the challenge and $7,10,13,16$, and $28 \mathrm{~h}$ after LPS infusion. Two measures of weight shifting between the rear legs were calculated for each recording session: the standard deviation of the weight applied to the legs over time and the frequency of steps. The LPS infusion resulted in a consistent case of clinical mastitis approximately $4 \mathrm{~h}$ after the LPS infusion, as assessed by the presence of visible swelling and elevated rectal temperature in all cows. However, control animals had a higher temperature $7 \mathrm{~h}$ after LPS infusion compared with treated animals (40.8 vs. $39.0^{\circ} \mathrm{C}$; standard error of the difference $=0.2$ ). Overall, weight shifting between the rear legs was decreased $7 \mathrm{~h}$ after the LPS infusion compared with baseline, and this

\footnotetext{
Received November 20, 2012.

Accepted January 22, 2013.

${ }^{1}$ Corresponding author: nchapinal@yahoo.com

${ }^{2}$ Current address: Department of Large Animal Clinical Sciences, University of Saskatchewan, Saskatoon, Saskatchewan, S7N 5B4, Canada.
}

decrease was not affected by treatment with flunixin meglumine. It is likely that weight shifting increases friction between the swollen udder and the legs, increasing the pain experienced by the cow. Thus, cows with endotoxin-induced mastitis avoided shifting weight, particularly at the times when the most severe signs of inflammation occurred. Further research is needed to assess the efficacy of flunixin meglumine in mitigating udder pain and the accuracy of behavioral measures such as weight shifting in assessing analgesia in cows with mastitis.

Key words: flunixin meglumine, lipopolysaccharide, nonsteroidal antiinflammatory drug, pain

\section{Short Communication}

Mastitis is a commonly occurring disease in the dairy industry (Olde Riekerink et al., 2008), with high associated economic costs (Halasa et al., 2007). Evidence exists that even mild to moderate cases of mastitis are painful (Milne et al., 2003; Banting et al., 2008; Fitzpatrick et al., 2013) and, therefore, it is a welfare concern. Traditionally, udder pain was assessed using subjective scales (Banting et al., 2008). Recently, Fitzpatrick et al. (2013) validated a pressure algometer that assesses pain sensitivity by measuring the maximum pressure applied to the udder that an animal is willing to tolerate. However, as pain sensitivity is subject to individual variability, changes in pain sensitivity have to be assessed within each animal. This requires continuous monitoring of the pain response, which can be challenging on farm, particularly as herd size increases. Fortunately, automated methods to continuously monitor pain-related behaviors are available. For example, lying behavior can be easily monitored using data loggers (Ledgerwood et al., 2010). Several studies (Siivonen et al., 2011; Cyples et al., 2012; Yeiser et al., 2012) have described a decrease in lying behavior in the hours following the experimental induction of mastitis. These results suggest that lying down at the time when the most severe signs of local inflammation occur causes pain, and that cows choose to stand to relieve 
the pressure exerted in the udder. However, little research exists on whether cows with mastitis also adapt the way they stand to minimize udder pain. Milne et al. (2003) described a greater distance from one hock to the other hock in cows with mastitis compared with healthy cows. It is known that cows increase weight shifting between legs as well as their stepping behavior (the most obvious form of weight shifting) when they stand for long periods of time on concrete or rubber (Chapinal et al., 2011; Krebs et al., 2011). Increases in weight shifting while standing have also been associated with painful cases of lameness (Rushen et al., 2007; Chapinal et al., 2010). However, it is possible that pain associated with mastitis results in less weight shifting and stepping behavior, whereas standing is a way for the cow to minimize pain in the udder. Anecdotally, Chapinal et al. (2011) reported a decrease in the ratio number of steps to actual weight shifting in a cow with naturally occurring mastitis; the cow was shifting most of the weight without lifting the hooves off the ground. Such changes in weight distribution and stepping behavior can be assessed automatically by using specialized weighing platforms (Chapinal and Tucker, 2012).

The availability of reliable automated methods to assess pain is the first step to evaluating treatments intended to relieve pain. Nonsteroidal antiinflammatory drugs (NSAID) are commonly used in cattle to alleviate inflammation, pain, and fever, although the analgesic effect of NSAID in dairy cattle is not well understood. Nonsteroidal antiinflammatory drugs have been reported to decrease udder pain in mastitis (Lohuis et al., 1991; Banting et al., 2008; Fitzpatrick et al., 2013). However, the efficacy of NSAID in counteracting the changes in behavior that are likely associated with mastitis pain or discomfort, such as lying behavior or rumination, is controversial (Zimov et al., 2011; Yeiser et al., 2012; Fitzpatrick et al., 2013). The objectives of this study were (1) to evaluate changes in weight shifting between legs while standing on a weighing platform in response to endotoxin-induced clinical mastitis and (2) to evaluate the effect of the NSAID flunixin meglumine on weight shifting between legs while standing in dairy cattle with endotoxin-induced clinical mastitis. Flunixin meglumine is approved by the US Food and Drug Administration for use in cattle to treat fever associated with mastitis, respiratory disease, and endotoxemia, and for the alleviation of inflammation in endotoxemia. In this study, we also monitored rectal temperature to evaluate the occurrence and duration of the clinical mastitis episode induced by the endotoxin, and the activity of the drug.

Nineteen lactating dairy cows were enrolled in this study from January to September 2011, in 7 groups of 2 to 4 cows at a time. Only animals with no clinical signs of illness and no history of treatment for illness in the last $30 \mathrm{~d}$ were selected. All animals were between 38 and 73 DIM (mean $\pm \mathrm{SD}=55 \pm 12 \mathrm{DIM}$ ). The study group was blocked into primiparous $(\mathrm{n}=10)$ and multiparous $(\mathrm{n}=9$; parity range $=2$ to 5$)$ groups. All animals were housed in a freestall facility at the North Dakota State University Teaching and Research Unit (Fargo). Cows were fed a TMR daily at approximately $0630 \mathrm{~h}$ and were milked daily at approximately 0430 and $1530 \mathrm{~h}$. All procedures involving animals were approved by the Institutional Animal Care and Use Committee at North Dakota State University.

Each animal was challenged in the right rear quarter with an intramammary infusion of $100 \mu \mathrm{g}$ of purified bacterial Escherichia coli LPS (from Escherichia coli 0111:B4; Sigma-Aldrich Co., St. Louis, MO) reconstituted in $20 \mathrm{~mL}$ of sterile saline solution. Only quarters with a negative California mastitis test and negative microbiological culture (after $24 \mathrm{~h}$ of incubation at $37^{\circ} \mathrm{C}$ ) $3 \mathrm{~d}$ before the challenge were eligible. The infusion was performed following morning milking (approximately at $0500 \mathrm{~h}$ ) on the challenge day after disinfecting the teat with an iodine-based teat disinfectant product. More details of the challenge procedure are described in Cyples et al. (2012).

Animals were randomly assigned to treatment within parity blocks (using a random number generator available at http://www.random.org) within parity blocks. Ten animals received flunixin meglumine (Banamine injectable solution; Merck Animal Health, Summit, NJ) at a dosage of $2.2 \mathrm{mg} / \mathrm{kg}$ (dosing volume $=1 \mathrm{~mL} / 22.7$ $\mathrm{kg}$ of $\mathrm{BW}$ ), and 9 received an equivalent volume of sterile isotonic saline solution (control group). Animals were weighed (mean $\pm \mathrm{SD}=635 \pm 121$; range $=548-$ $715 \mathrm{~kg}$ of BW) the day before treatment to calculate individual dosages. The injections were administered by bolus injection in the left jugular vein approximately $4 \mathrm{~h}$ after the LPS infusion (at approximately $0900 \mathrm{~h}$ ).

Body temperature was monitored rectally using a digital thermometer (GLA Agricultural Electronics, San Luis Obispo, CA) 3 d before LPS infusion (at approximately $0830 \mathrm{~h}$ ), immediately before the LPS infusion and 4, 7, 10, 13, 16, and $28 \mathrm{~h}$ after LPS infusion. Data collected before the LPS infusion were averaged to obtain 1 baseline value per cow.

The weight applied to each leg was recorded while cows were standing on a weighing platform (Pacific Industrial Scale Co. Ltd., Richmond, BC, Canada), as described in Chapinal et al. (2010). In brief, the platform contained 4 stainless steel independent recording units $(12 \mathrm{~cm}$ high $\times 59 \mathrm{~cm}$ wide $\times 99 \mathrm{~cm}$ long $)$, each containing 4 stainless steel load cells (3 mV Shear Beam Load cells; Anyload LLC., Santa Rosa, CA; maximum capac- 
ity $=454 \mathrm{~kg}$ for each load cell). Data were transmitted to a computer at a rate of approximately 14 readings/s. Specific software (CowWeigh.exe version 2.2; Pacific Industrial Scale Co Ltd.) was used to provide a real-time display of the weight applied to each of the 4 units. A manual steel squeeze $(2.1 \mathrm{~m}$ high $\times 2.0 \mathrm{~m}$ long $\times 1.3$ $m$ wide) was mounted on the platform to restrain the cows. The weighing platform was situated at the end of a passageway. For data collection, cows were gently walked onto the platform were they stood for $5 \mathrm{~min}$ at a time. Cows were released and walked again onto the platform between consecutive 5-min periods. At least $24 \mathrm{~h}$ before the start of data collection, cows were acclimated to the scale by standing on it for at least 3 periods of 5 to $10 \mathrm{~min}$ each.

Weight distribution while standing on the scale was recorded for 3 periods of $5 \mathrm{~min}$ on the day before the challenge (at approximately $1000 \mathrm{~h}$ ) and 7, 10, 13, 16, and $28 \mathrm{~h}$ after LPS infusion. Two measures of weight shifting were calculated for each 5-min period: (1) the standard deviation of the weight applied to the rear legs over time (Rushen et al., 2007) and (2) the frequency of steps taken with the rear legs, calculated with the algorithm described in Chapinal and Tucker (2012). The ratio number of steps to standard deviation of the weight applied to the rear legs was calculated for each 5 -min period to assess how much of the weight shifting was due to stepping. Data across the three 5-min periods were averaged to obtain 1 value per cow and sampling time.

All statistical analyses were performed with SAS (version 9.3; SAS Institute, Inc., Cary, NC), considering cow as the experimental unit. Data were analyzed using mixed models (PROC MIXED) that included time as a repeated measure over cow, parity (primiparous or multiparous), and treatment as fixed effects, and the biologically plausible 2 -way interactions. The covariance structure was selected based on the smallest Akaike information criterion. Variables and interactions were removed from the final model if $P>0.05$. Contrast statements were used to test differences between baseline and subsequent time periods, or between treatments at individual time periods. Residuals were examined to verify normality and homogeneity of variances and to detect possible outliers and influential points.

The LPS infusion resulted in a consistent, moderate to severe case of clinical mastitis approximately $4 \mathrm{~h}$ after the LPS infusion, as assessed by the presence of visible swelling and elevated rectal temperature in all cows. When rectal temperature was analyzed, we found an interaction between treatment and time period $(P$ $<0.001$; Figure 1). Control animals had a higher and later peak temperature, such that a significant difference existed between control and treated animals 7

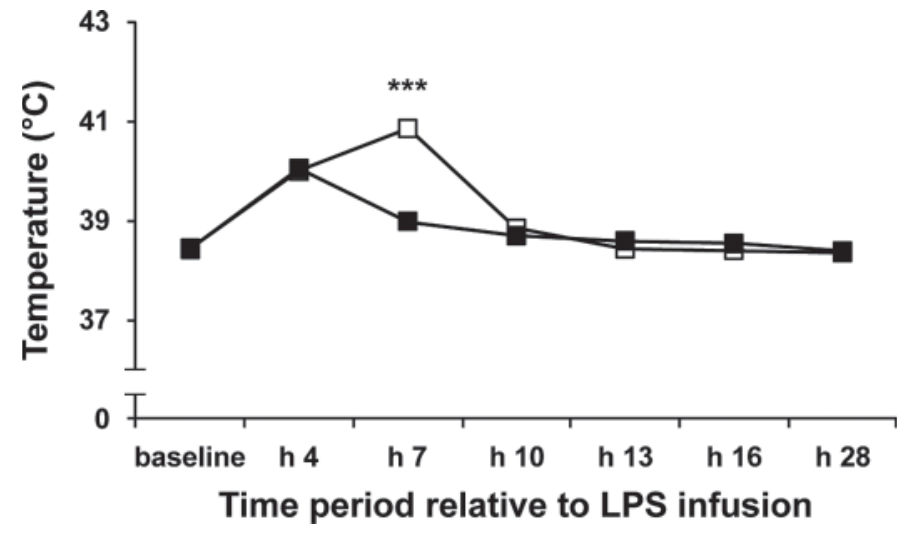

Figure 1. Least squares means $( \pm \mathrm{SE})$ body temperature $\left({ }^{\circ} \mathrm{C}\right)$ of freestall-housed dairy cows before (baseline) and after (h 4 to 28) intramammary infusion with Escherichia coli LPS after morning milking. Cows were injected approximately $4 \mathrm{~h}$ after LPS infusion with either flunixin meglumine $(\mathrm{n}=10$; $)$ or an equivalent volume of saline solution $(\mathrm{n}=9 ; \square)$. The $\mathrm{SE}$ are too small to be visible. Baseline data were calculated as an average of the temperature measured $3 \mathrm{~d}$ before and immediately before LPS infusion. ${ }^{* * *} P<0.001$ when comparing the 2 treatments $7 \mathrm{~h}$ after LPS infusion.

$\mathrm{h}$ after LPS infusion $\left(40.8\right.$ vs. $39.0^{\circ} \mathrm{C}$ for control and treated animals, respectively; standard error of the difference $=0.2 ; P<0.001)$. These results confirm the antipyretic efficacy of flunixin meglumine in cases of endotoxin-induced mastitis, as described in previous studies (Anderson et al., 1986; Wagner and Apley, 2004; Zimov et al., 2011).

The weighing platform data from 2 cows were discarded for the analysis: one cow was identified as lame during the study and one presented an extremely high standard deviation of the weight applied to both the front and rear legs throughout the study. Overall, multiparous cows had a greater standard deviation of the weight applied to the rear legs than primiparous cows $(25.9$ vs. $18.7 \mathrm{~kg}$; standard error of the difference $=$ $1.2 ; P<0.001)$. After controlling for parity, a decrease was observed in the standard deviation of the weight 7 $\mathrm{h}$ after the LPS infusion compared with baseline $(P=$ 0.03 ; Figure $2 \mathrm{~A}$ ). Flunixin meglumine did not have an effect on the standard deviation of the weight applied to the rear legs $(P>0.05$ for treatment and treatment $\times$ time). The standard deviation of the weight applied to the rear legs was correlated to the frequency of steps taken with the rear legs $(\mathrm{r}=0.55 ; P<0.001)$ and, therefore, results were very similar (Figure $2 \mathrm{~B}$ ). As a result, no effects were observed of the LPS infusion or treatment on the ratio number of steps to standard deviation of the weight applied to the rear legs $(P>$ 0.05 for treatment, time, and treatment $\times$ time).

These results suggest that cows with endotoxininduced mastitis avoided shifting weight both with and without lifting the hooves from the ground while stand- 


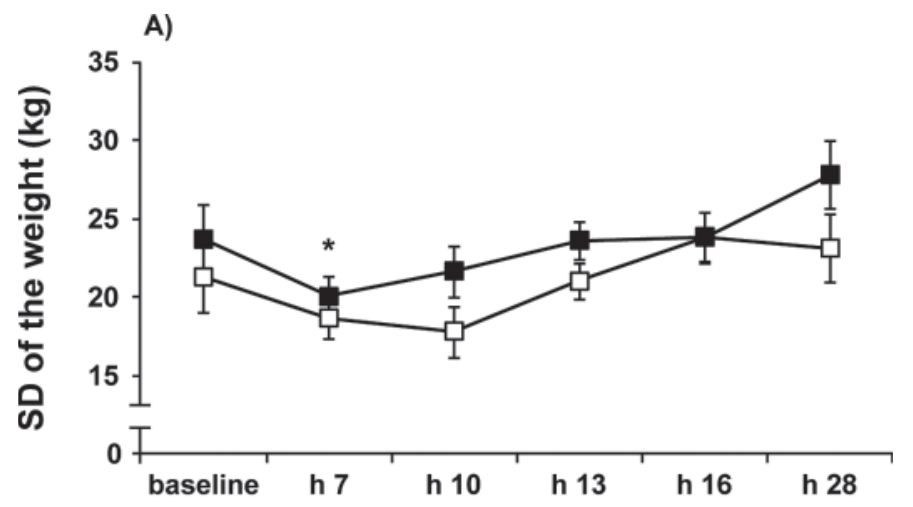

B)

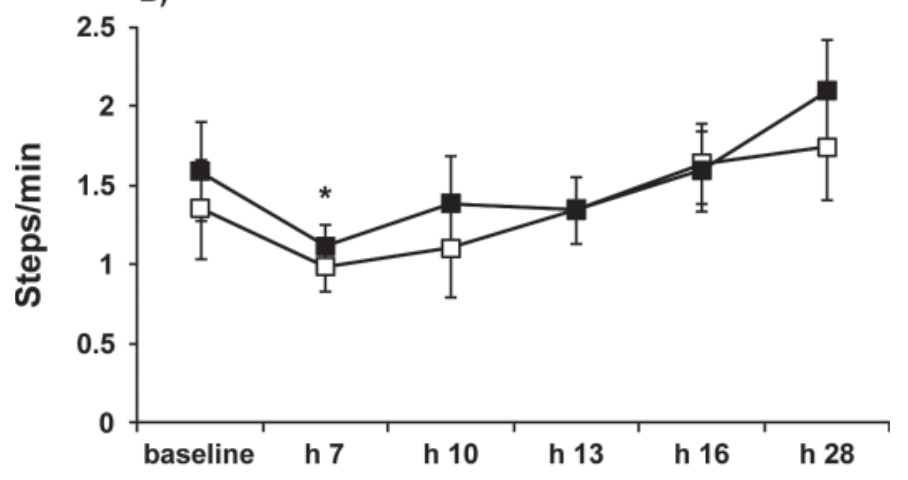

Time period relative to LPS infusion

Figure 2. Least squares means $( \pm \mathrm{SE}) \mathrm{SD}$ of the weight applied over time to the rear legs (A) and frequency of steps taken with the rear legs (B) of freestall-housed dairy cows before (baseline) and after (h 4 to 28) intramammary infusion with Escherichia coli LPS after morning milking. Cows were injected approximately $4 \mathrm{~h}$ after LPS infusion with either flunixin meglumine $(\mathrm{n}=9$; $\mathbf{0})$ or an equivalent volume of saline solution $(\mathrm{n}=8 ; \square) .{ }^{*} P<0.05$ when comparing baseline to $7 \mathrm{~h}$ after LPS infusion, considering the 2 treatments together.

ing, particularly at the times when the most severe signs of inflammation occurred. It is likely that weight shifting increases the friction between the swollen udder and the legs, increasing the pain experienced by the cow. This hypothesis is along similar lines to the observed increase in hock-to-hock distance in mastitic cows reported by Milne et al. (2003). Contrarily, Medrano-Galarza et al. (2012) monitored weight shifting between legs for $10 \mathrm{~d}$ after diagnosis of mild natural-occurring cases of mastitis and found that weight shifting was greater on the day of the diagnosis compared with $10 \mathrm{~d}$ after treatment (no baseline data were collected). However, they could not familiarize the cows with the weighing platform before data collection, and as they also found a decrease in weight shifting over time in the control group, they concluded that the observed changes were likely the result of cows habituating to the platform. Increases in weight shifting between legs have also been observed in painful cases of lameness
(Rushen et al., 2007; Chapinal et al., 2010). All in all, these results highlight the importance of continuously monitoring changes in weight shifting within cows to identify abnormalities (in either direction) and complementing that information with other clinical signs to diagnose the specific ailment. In large herds, this can be achieved by installing weighing platforms in automatic milking systems and setting alarms when changes in weight shifting within an individual surpasses a certain threshold (Pastell and Kujala, 2007).

Treatment with flunixin meglumine did not counteract the decrease in weight shifting between the rear legs. This could be due to a lack of analgesic effect of flunixin meglumine or weight shifting not being a sensitive-enough measure to monitor analgesia in cows with endotoxin-induced mastitis. In a previous study, the increase in weight shifting caused by lameness was counteracted by the injection of ketoprofen (Chapinal et al., 2010), suggesting that weight shifting was a sensitive measure to detect the analgesic effect of ketoprofen in lame cows. The analgesic effect of flunixin meglumine in mastitis has not been well studied and is inconsistent across studies, as assessed by indirect indicators of pain in experimentally induced cases of mastitis such as udder swelling (Anderson et al., 1986; Wagner and Apley, 2004; Zimov et al., 2011) or lying behavior (Zimov et al., 2011; Yeiser et al., 2012). Further research is needed, particularly with naturally occurring cases of mastitis, to assess the efficacy of flunixin meglumine in mitigating udder pain as well as the accuracy of behavioral measures such as weight shifting in assessing pain and analgesia in cows with mastitis.

\section{ACKNOWLEDGMENTS}

The authors thank the management and staff of the North Dakota State University Dairy Teaching and Research Unit (Fargo). The study was generously funded by Merck Animal Health (Summit, NJ). N. Chapinal was supported by a Beatriu de Pinós postdoctoral grant from the Generalitat de Catalunya (Barcelona, Spain).

\section{REFERENCES}

Anderson, K. L., A. R. Smith, R. D. Shanks, L. E. Davis, and B. K. Gustafsson. 1986. Efficacy of flunixin meglumine for the treatment of endotoxin-induced bovine mastitis. Am. J. Vet. Res. 47:13661372 .

Banting, A., S. Banting, K. Heinonen, and K. Mustonen. 2008. Efficacy of oral and parenteral ketoprofen in lactating cows with endotoxin-induced acute mastitis. Vet. Rec. 163:506-509.

Chapinal, N., A. M. de Passillé, J. Rushen, and C. B. Tucker. 2011. Measures of weight distribution and frequency of steps as indicators of restless behavior. J. Dairy Sci. 94:800-803.

Chapinal, N., A. M. de Passillé, J. Rushen, and S. Wagner. 2010. Automated methods for the detection of lameness and analgesia in dairy cattle. J. Dairy Sci. 93:2007-2013. 
Chapinal, N., and C. B. Tucker. 2012. Validation of an automated method to count steps while cows stand on a weighing platform and its application as a measure to detect lameness. J. Dairy Sci. 95:6523-6528.

Cyples, J. A., C. E. Fitzpatrick, K. E. Leslie, T. J. DeVries, D. B. Haley, and N. Chapinal. 2012. Short communication: The effects of experimentally induced Escherichia coli clinical mastitis on lying behavior of dairy cows. J. Dairy Sci. 95:2571-2575.

Fitzpatrick, C. E., N. Chapinal, C. S. Petersson-Wolfe, T. J. DeVries, D. F. Kelton, T. F. Duffield, and K. E. Leslie. 2013. The effect of meloxicam on pain sensitivity, rumination time, and clinical signs in dairy cows with endotoxin-induced clinical mastitis. J. Dairy Sci. 96:2847-2856. http://dx.doi.org/10.3168/jds.2012-5855.

Halasa, T., K. Huijps, O. Østerås, and H. Hogeveen. 2007. Economic effects of bovine mastitis and mastitis management: A review. Vet. Q. 29:18-31.

Krebs, N., S. L. Berry, and C. B. Tucker. 2011. Restless behavior increases over time, but not with compressibility of the flooring surface, during forced standing at the feed bunk. J. Dairy Sci. 94:97-105.

Ledgerwood, D. N., C. Winckler, and C. B. Tucker. 2010. Evaluation of data loggers, sampling intervals, and editing techniques for measuring the lying behavior of dairy cattle. J. Dairy Sci. 93:5129-5139.

Lohuis, J. A. C. M., T. van Werven, A. Brand, A. S. J. P. A. M. van Miert, E. Rohde, B. Ludwig, P. Heizmann, and W. F. Rehm. 1991. Pharmacodynamics and pharmacokinetics of carprofen, a nonsteroidal anti-inflammatory drug, in healthy cows and cows with Escherichia coli endotoxin-induced mastitis. J. Vet. Pharmacol. Ther. 14:219-229.
Medrano-Galarza, C., J. Gibbons, S. Wagner, A. M. de Passillé, and J. Rushen. 2012. Behavioral changes in dairy cows with mastitis. J. Dairy Sci. 95:6994-7002.

Milne, M. H., A. M. Nolan, P. J. Cripps, and J. L. Fitzpatrick. 2003. Assessment and alleviation of pain in dairy cattle with clinical mastitis. Cattle Pract. 11:289-293.

Olde Riekerink, R. G. M., H. W. Barkema, D. F. Kelton, and D. T. Scholl. 2008. Incidence rate of clinical mastitis on Canadian dairy farms. J. Dairy Sci. 91:1366-1377.

Pastell, M. E., and M. Kujala. 2007. A probabilistic neural network model for lameness detection. J. Dairy Sci. 90:2283-2292.

Rushen, J., E. Pombourcq, and A. M. de Passillé. 2007. Validation of two measures of lameness in dairy cows. Appl. Anim. Behav. Sci. 106:173-177.

Siivonen, J., S. Taponen, M. Hovinen, M. Pastell, B. J. Lensink, S. Pyörälä, and L. Hänninen. 2011. Impact of acute clinical mastitis on cow behaviour. Appl. Anim. Behav. Sci. 132:101-106.

Wagner, S. A., and M. D. Apley. 2004. Effects of two anti-inflammatory drugs on physiologic variables and milk production in cows with endotoxin-induced mastitis. Am. J. Vet. Res. 65:64-68.

Yeiser, E. E., K. E. Leslie, M. L. McGilliard, and C. S. Petersson-Wolfe. 2012. The effects of experimentally induced Escherichia coli mastitis and flunixin meglumine administration on activity measures, feed intake, and milk parameters. J. Dairy Sci. 95:4939-4949.

Zimov, J. L., N. A. Botheras, W. P. Weiss, and J. S. Hogan. 2011 Associations among behavioral and acute physiologic responses to lipopolysaccharide-induced clinical mastitis in lactating dairy cows. Am. J. Vet. Res. 72:620-627. 